\title{
March 4th, 1977 - the year when a new medical specialization appeared
}

\author{
Liviu Constantin \\ University of Bucharest, Faculty of Geography
}

\begin{abstract}
This article represents a short history of how the "operational medicine" appeared in Romania (the sum of specific activities in the domain of the military emergency medical assistance based on the logistics and specific medical evacuation, according to the goal of the mission and the operational demands). The operational medical support (OMS) represents the medical specialization derived from the battle technique brought to the civilian level. The repeated sorting of victims at each rescue stage represents the essence of the new medical specialization appeared in March 4th, 1977. At present, this specialization must incorporate the advantages of the space technology.
\end{abstract}

Key words: operational medical support, repeated sorting, space technology

The natural disaster, the earthquake which affected Romania in March 4th, 1977 at 9:22 p.m. might have caused even more victims, according to the simulation exercises conducted in that period, but especially according to the electronic and medical intervention simulation exercises conducted after the 2000s (Buhoiu, 1977, Steiner, 2004). Measuring 7.2 on the Richter scale and lasting approximately 55 seconds, the earthquake caused about 1570 victims nationally out of which 1400 in Bucharest. The exemplary mobilisation of human and material resources highly diminished the number of the deceased. The state of emergency was established by Order in Council which relied on the army, military firefighters, military athletes, civilians instructed by the Patriotic Guards and ... stuntmen*. Whereas after the events of September 11th, 2003 an institution to deal with the medical assistance was founded in the United States - "The National Disaster Medical System (NDMS) - Romania

\footnotetext{
* The director Sergiu Nicolaescu organized the first team of stuntmen in Romania. Those were recruited especially among sportsmen: rugby players, athletes, canoeists, fencers (the sports-clubs belonged to the army or to the Ministry of Internal Affairs). The stuntmen from Buftea were in the first line during the rescue operations of the victims caused by the earthquake in 1977, taking more than 150 people out of the ruins.
}

benefitted from a military emergency medical specialisation after the ill-fated day of the earthquake in 1977. At that time, the national army wasn't involved in operational missions beyond the borders of Romania as a result of the national policy of non-interference in the internal affairs of other countries. The best example of this would be when the Romanian army did not involve itself in the invasion of Czechoslovakia in August 21st, 1968. The real combat experience and especially the humanitarian aid experience were strictly limited to the exercises of "Instruction for the country defense", the extension to the population being insured by the organisations called Patriotic Guards and Civil Defense or the Red Cross (the telling argument would be the participation of Romania in the war from Korea when the Romanian Red Cross built a hospital where there were more than 220 healthcare practitioners to support the Koreans together with the US and China, as Prof. M.D. Corneliu Butnaru states - radiologist during the War in Korea). Nevertheless, the military and civil staff paid a special attention to the training in case of natural hazards, but especially to man-made disasters. We mention the actions at national and international level undertaken by the oil industry 
workers and the military fire fighters and even of the army during disasters caused by the setting on fire of the derricks, offering medical help to the victims on the spot. Thus, there was a real practical side, and not only trainings, which assessed the correct application of the normative conceptual organizational plan in the development of the specific activities, leading to generous debates of ideas among soldiers and civilians, especially regarding the medical problems and operational support (MOS) offered to the civilian victims during disasters.

Oil, the "black gold" is indissolubly linked to Romania throughout its history. The first oil distillery in the world was built in Romania, which laid the foundation of the most important industry of the world, and Bucharest was the first city lit up with lamp oil. Moreover, Romania was the first country in the world with oil production officially recorded in the international statistics. "The Science of Petroleum" certifies in 1938 the fact that Romania had been the first country in the world with an oil production of 275 tonnes in 1857. It was followed by the USA in 1859, Italy in 1860, Canada in 1862 and Russia in 1863 (Adevarul, 2015). Under these circumstances, the first oil worker rescue teams were established whose duty was to localise and eliminate the incidents and accidents occurring at the derricks, work places which were extremely dangerous back to those times. Together with the quick development of the oil industry and the modernizing and massive industrialization of Romania between the ' $60 \mathrm{~s}$ and the $80 \mathrm{~s}$, the oil worker's role of being a rescuer too led to the appearance of the double specialization of certain specialists as rescuers for the first time worldwide. The concept was based on the fact that during the first minutes and/or hours from the occurrence of a disaster, the person on the spot had to help their mates unconditionally, especially if they were trapped together and the rescue was belated. There were many tragic and spectacular at the same time events, reason why the movie "Subteranul" (Underground) is released in 1967, a Romanian movie about a fire breaking out at the oil derrick "Neagra" following a failed research experiment. There were other movies, too, showing rescue oil workers' interventions in countries from the East (during the years 1970-1989 Romania was an important provider of oil technology), where their professionalism was always appraised. The movie was watched by $1,490,872$ people in the cinemas of Romania (the movies also had an educational aim) as attested by the National Centre of Cinematography which drew a statistic of the number of viewers registered for the Romanian movies starting with the date of the premiere till December 31st, 2014. (Centrul National al Cinematografiei, 2014). Nowadays, the disappearance of the specialists in the oil domain and especially of the rescuers had as a result Raed Arafat's announcement, the coordinator of the Control Department for Emergency Situations that the fire started at some oil derrick "will last long until extinction", announcement made on Digi24 TV channel (2017). "There are very special procedures for this kind of intervention, considering we are talking about foreign rescue teams". Later on, the concept of rescue-professional was introduced in all risky industries, reaching its peak with the subway in Bucharest, where we can find at present rescue departments in the important subway stops. The concept of professional rescuer disappeared after the $90 \mathrm{~s}$ together with the destruction of the Romanian educational system. The Army was the only to keep this concept after the 90s and subsequently developed it during the collaboration with the NATO partner armies.

Medical operational support (MOS) represents the sum of specific activities in the domain of the military emergency medical assistance based on the logistics and specific medical evacuation, according to the goal of the mission and the operational demands. This kind of mission is generally oriented to the medical ones, each mission having a humanitarian objective of supporting life, security, logistics and defence. The main element of MOS is the ability of self-support of this kind of special units with special attention to the help given to the operational staff and then to the civilians. The medical staff taking part in MOS was considered more than a provider of primary medical healthcare in emergency, focusing on prevention and the environmental risk. In the case of the army or military firefighters ' actions during man-made disasters such as those happening at the oil derricks, the 
operational interventions cannot be perfectly framed as planned. The action could last from days to months.

Such teams were made up of a military generalist doctor, a nurse and a couple of soldiers, miners, oil workers or firefighters as emergency medical technicians. These teams were trained in a pre-hospital environment, focusing on the independent way of acting in a well-defined medical structure. MOS concentrated on the military line of medical healthcare at strategic and operational levels within the lines corresponding to the logistic support. The method of offering medical operational support was directed differently according to the type of civil or military foreseen disaster (above ground or underground). Specialised medical help must be permanently offered to the sick and wounded in the process of the rescue actions. The time of the medical intervention was considered decisive for the saving and stabilization of the wounded respectively their survival and healing.

The military rescue system of civilians in natural or man-made disasters was based on the rules stated in the Agreements from Geneva (WHO, 1997), on the model of the six hours or the golden hour. In this period the starting of MOS at the place of disaster, the selection and the medical evacuation didn't need other procedures or approvals. Nowadays, the Agreements from Geneva which regulate these rescue and emergency healthcare mechanisms stipulate that MOS should insure the wounded's transport to the specialized healthcare structures (e.g. surgery) within an hour and not later than four hours from the occurrence of a disaster. In case of need (the impossibility of evacuation) this amount of time can be extended with two more hours by providing emergency healthcare or surgery. MOS relied mainly on mobility and availability, insuring the resources, complete recovery, professional authority. The healthcare provided by MOS to the civilians is identical to the one offered on the battlefield. Only the circumstances and priorities at the place of disaster differ (Craciun, 2001).

The repetitive sorting pattern at each stage of the medical rescue chain was one of the key elements of minimizing deaths during the 1977 earthquake in Romania. Sorting based on experience led to the reduction of the deceased number. That year, soldiers, but also technical civil staff (the engineers and workers proved to be much more rigorous than it is believed that they are today) obeying the order given by the MOS responsible chosen on the spot, made the sorting take place under most favourable conditions, even if the resources were much diminished and the emergency healthcare system seemed blocked. While at the place of disaster (where the victim was taken out) there was a primary but experimented type of sorting at the next level (e.g. transport) the victim was reconsidered and a new revaluation was performed in the hospital, the process going on continuously. There were separated sorting and treatment areas to prevent the evacuation of victims made by wellintended people who weren't part of MOS. The application of military rules during the natural disaster by finding evacuation ways specific to the army made the evacuation be conducted quickly and safely without deceased in the process (there is no information). The registered deaths were only those on the spot of the disaster. The civilians part of MOS as mentioned above, belonged mainly to the construction, industry, and technical domains. For instance, each industrial or agricultural civil unit had organisations such as Patriotic Guards or Civilian Defence which were periodically trained in case of disasters, especially in case of a direct bombing attack. Thus, there were many civilians who had military training not only because of the obligatory military instruction undergone both by boys and girls (later on only for boys) at 18 years, but also by going on with the military instruction as part of the organisations mentioned above. At the moment of the 1977 earthquake, most of the civilians could cooperate with the army, this being the key element of the reduced number of victims. The stuntmen, as particular element of the phenomenon, accomplished successfully numerous actions ordered by the military staff. The evidence given by rescue stuntmen such as Mircea Pascu or Paul Fister are touching. This is what Mircea Pascu declared: 'I heard some cries and we started digging... as far as the third floor. We crawled under those ceilings, we took the debris away and we found the first survivor from the third floor' or Paul Fister: 'The image of those crushed people 
makes me shiver even today. I saw people's heads like crushed cigarette ends... I couldn't even drink the coffee brought by those in the Patriotic Guards anymore, nor the tea from the Red Cross. When you felt that sweet taste, you started thinking of the smell of death immediately. People asked to bury them like Christians... We crossed ourselves and carried them I, by the hands and Tudorica Stavru, by the legs... Today I would do the same. If you're 73 , does it mean that you lack courage?'. This is the article in the online newspaper 'adevarul.ro'. If we also mention that the medical system at that time was subject to a rigour reminding the military one, the sick with TB being monitored like soldiers on duty (in 1989 there were few sick with TB, the disease being eradicated just like many other infectious diseases which re-emerged massively after the '90s) and the medical mistakes (malpraxis) were punished with jail, we have the image of an extremely rigorous civil action. The emergency military system for civilians (EMSC) with its military medical emergency specialisation for civilians (MMEC) was founded in March 4th, 1977 (Chertic, 1995, Nicolae and Dan, 1995). The present commander of the Central Military Hospital states: 'It was the first important mission to support the population affected by the disaster, when one must be militarized to answer appropriately for the actions to develop well'. (general Florentina Ionita Radu) (Romania Actualitati, 2016).

We can also mention the military instruction imposed to the firefighters to support the above information. After the '90s, firefighters were transferred to the army as military firefighters, within the Ministry of Internal Affairs. The militarized ambulances belonging to these firefighters represent another argument to support the idea that in emergency case or disaster, the emergency system must be military coordinated.

Paying attention to other events, it is hard to forget the tragic crash of the transplant medical plane in 2014, when misused or basically used technology may have led to the death of some rescuers instead of helping to localise and save them. If the doctor who used the communication technology at the moment of the plane crush had had elementary knowledge of Geography which to corroborate with a military type of thinking (if he had had elementary military instruction) telemedicine and remote sensing would have worked to their advantage (nowadays smart phones can replace a part of applications).

'Many people from different institutions able to interfere in emergency didn't manage to locate the place of the plane crush hours on end yesterday, even though the survivors called 112 and communicated with the rescue team permanently. The plane wreck and victims were found by a forester after a five-hour search. The pilot Adrian Iovan asked the doctor Zamfir to save him as he was caught in the wreckage. 'I tried to pull him out but I couldn't. Subsequently (Iovan) became unconscious' the doctor said. Adrian Seceleanu writes in his article "This case proves again the inflation of institutions in Romania and their inability to coordinate at critical moments" (Public Health Emergency, 2017). The opposite example is the case of an Israeli tourist who was perfectly located and saved by the mountain rescuers after using the same type of technology (smart phone) in 2017. The case was mentioned by the local press: "The tourist made the bad decision to follow a shortcut, which represented a real danger. $\mathrm{He}$ reached an area difficult to access but finally the mountain rescue team from Arges succeeded in finding and taking him out from that area." (Ziarul financiar, 2014)

The evaluation of victims from the distance in case of lack of MOS and experimented first aid staff using the telemedicine (using the smart phone) has become necessary modernization, not only a desire for the future. Thus, persons without qualification can be used and be guided to collect medical information. However, the MOS system must be revigorated together with the purchase of medical informational technology, remote sensing techniques and telemedicine excluding the business domain and getting into the social environment of rescue in case of disaster. In this case, it would be desirable that the mobile telephony companies should stop imposing taxes on the users and allow free audiovideo access to the emergency medical staff, either civil or military (they should only be registered in the telephony company data base as rescue staff). We recently could follow the campaign and struggle for getting permission to transmit a common warning message on the smart phone in case of an 
earthquake and the opposition of the private companies. The need of a militarily controlled communication line would be one more solution of telemedicine.

The modern exercises such as 'Cetatea, 2014' to assess the components of the informational and communication system of our army had as aim dealing with the civilian emergency situations generated by natural disasters. The soldiers, civilians and staff of the Ministry of Internal Affairs collaborated to achieve the technical exercise. The new approaches of MOS prove that the medical support is different for every operation since it needs to be adapted to what happens at the place of disaster no matter the special conditions of the action (e.g. battlefield). As a drop in the number of the medical loss and of the hospitalisation period is aimed at, MOS must be started automatically within the golden hour. The distance of evacuation must be analysed according to the distance of disposing compared to the military medical emergency action area. As shown above, MOS is part of the logistic support system, holding all the execution and management organs of the medical support and their relations. The latest interoperability exercises at NATO level, such as the SARMIS 15 type, show that our professionals in the military and sanitary domains have been highly appreciated for their professionalism and strictness they proved, and demonstrated they are able to apply the best medical practice in case of military or disaster situations. "We have worked with the soldiers and the military medical staff in the allied armies very well and we have proved we are interoperable at NATO standards" as 1t.col. dr. Derioiu Daniel, the coordinator of the medical military forces involved in the exercise, mentioned in an interview in 2015 (Armata Romaniei, 2015). The general objectives of certain technical exercises of military medical emergency given to civilians in peacetime in case of natural disasters, represent the training of special structures as to planning, projecting, implementing, managing and insuring the communication/ data processing services as well as the security of the command and control networks to support the military actions directed towards the population in the areas of the natural disasters, as it is mentioned once again by lt. col. dr. Derioiu Daniel (Armata Romaniei, 2015).

The reform of the military medical system started by col. dr. Eremie Adrian in the Medical Department of the Ministry of National Defence has as aim new conceptions of medical insurance of the army in peacetime and/or during war. There must be short-term and very short-term projects (a natural disaster cannot be announced), starting with centralizing the effects and medical services at global civil and military level to make them interoperable and obeying to an only command (Top de Arges, 2017, Craciun, 2001).

Let's not forget that Romania took part in UN PKOs after the '90s: UN observation mission in Irak-Kuweit (UNIKOM) April 1991 - October 2003, 10 military observers (MilObs); UN observation mission in Somalia (UNISOM-II), March 1993 - March 1995, a military field hospital (236 staff members); UN examination mission in Angola (UNAVEM - III), May1991 - June 1997, 36 general staff officers and military policemen, an infantry battalion (751 soldiers) and a military field hospital (110 staff members); UN observation mission in Angola (MONUA), August 1997 February 1999, an infantry subunit (156 soldiers); UN mission in Bosnia and Herzegovina (UNMIBH), 1995 - December 2005, 10 MilObs; UN Interim Administration mission in Kosovo (UNMIK), launched in July 1999, 1 MilObs; UN observation mission in DR Kongo (MONUC) launched in November 1999 - Romania started its participation with 5 liaison officers. From July 1st, 2010, the UN observation mission was transformed into UN stabilisation mission in DR Kongo (MONUSCO). At present, Romania is taking part with 22 MilObs; UN observation in Cote d'Ivoire (UNOCI), launched in April 2004, 6 MilObs; UN mission in South Soudan (UNMISS) launched in July 9th, 2011, 6 MilObs; ONU mission in Libia (UNMIL) launched in September 19th, 2003, 2 MilObs; UN assistance mission in Afghanistan (UNAMA) launched in 2002, 2 MilObs.

The first participation of the Romanian Army in a conflict area was with medical teams. A field hospital was sent to provide medical assistance in the first war in the Gulf, Gen. Dr. Ion Dragusin's 
special activity as a commander of the field hospitals with 236 staff members at UNOSOM II and UNAVEM III with 110 staff members, coordinated by the Manager of the Medical Department - at that time - gen. Dr. Petru Chertic, raised the management of the MOS medical operations given to civilians at international levels (in 1995 he lays the foundations of the Congress of the Balkan Committees of Military Medicine, BCMM, having as partners his Greek and Turkish counterparts). At this moment BCMM hold specialists belonging to the military medicine services from Albania, Bulgaria, Greece, Romania, Serbia and Turkey. The scientific collaboration which is promoted brings its essential contribution to the increase of the visibility of the military medical activity in the Balkan area. "The two field hospitals treated numerous civilians caught in the war and even assisted births, thus our hospitals being ranked as ROL1 - ROL 4", as gen. Florentina Ionita Radu, the commander of the Central Military Hospital states (WHO, 1997). The reputation of the Romanian medical staff got to the UN General Secretary. Gen. Dragusin remembers "when Boutros Boutros Ghali visited the UN troops in Somalia, he organized his press conference in the Romanian hospital in the airport". Gen. Dragusin went back to the battlefield in 1995, when he commanded another Romanian field hospital in Angola. (Stiri TVR, 2013)

At this point some question rises. If, at present, the Romanian military doctors are perfectly inter-operable with the NATO soldiers, will they be able to rise to the level of those in the year 1977? If yes, then the civilians have been trained with military rigour and have first aid and sorting knowledge just like the ones trained within the Patriotic Guards in the old system. Moreover, do we still have a "Codex alimentarium" which today stipulates an easily obtainable Mediterranean diet to eliminate or correct the changes occurring in the metabolic syndrome and reduce the cardio-vascular risk as side effects in natural disasters? And which are the standards of the psychiatric emergency in case of disaster nowadays?

For example, in the US, "The National Disasters Medical System" (NDMS) is based on the former soldiers who are veterans. In fact, NDMS is a federal half militarized organism under governmental control and coordinated by the Department of Public Health (HHS) and the Department of Defence (DOD), Citizen Safety (DHA) and Veteran Affairs (VA). The organisation is made up of independent teams such as the Disaster Medical Assistance Team, the Coordinating and Response during Civil Accidents Team, Medical and Surgical Response Team, the Operational Team for Decease Response, the Federal Coordination Centre, the Centre for Victim Identification and the Veterinarian Incident Response Team. This organization has been reorganized many times and, at present it deals with incidents from pandemic and climatic disasters. There are also direct collaborations with governmental and local institutions and organisations, such as the Administration for Children and Family (ACF), Substance Abuse and Mental Health Services Administration (SAMNSA), National Centre for Medical Assistance (CMAS) and Centre for Disease Control and Prevention (CDC). (Romania actualitati, 2016)

In the civil area, the Romanian reform started with the partnership between the Department for Emergency Situations and the company Qualitance, in which certain applications of the mobile multifunctional telephony are addressed to the resident doctors specializing in emergency medicine, hoping that these applications will help them achieve and monitor the medical activities and procedures more rapidly. Moreover, the application is expected to facilitate the collaboration between doctors and their guides by simplifying the assessment and validation mechanism. "This new mobile application helps 500 doctors making their activity easier and more efficient and it also helps the patients since the doctors have more time available to treat them. As a result, the reporting and validation mobile application supports the DSU commitment of coming closer to the doctor's and patient's needs and the partnership with Qualitance is one more step in the right direction", dr. Raed Arafat said (Ziarul financiar, 2014).

When will the telemedicine technology and the DSU mobile applications have the same objectives as those from the Ministry of National Defence, 
facilitating the interoperability between civil and military doctors?

Unfortunately, these days the emergency military medicine for civilians is called "operational medicine". This naming could be explained by the fact that we need to forget that once there was an operational medical department. We leave the linguists decide if medicine is "operational" or the services can be "operational". Another idea would be that the "operational medicine" is the one focusing on the latest technical and informatic research with operational systems, algorithms, and medical decision based on theories of analytic mathematics in close relationship with medical ethics to strictly coordinate such a system. The logistic elements found in the army can be transferred to medicine for predictions and quick and real diagnosis, for efficient and quality operations to the highest degree. Such analysis was realised on the disaster in Japan in March 11th, 2011, when, after the earthquake the devastating effect was the one produced by the tidal waves and the radioactive leakage of the destroyed nuclear plant (Stiri TVR, 2013).

Foundations, such as Whitaker, established in 1998, deal with this of phenomena, reason why we understand that any reference to the "operational" medicine before 1998 are odd. All is left is the operational medical support offered by the emergency military services offered to the civilians as basic definition of this concept which appeared in Romania in March 4th, 1977. Anyway, in our opinion the emergency services must consider the new technic discoveries, such as telemedicine and the rational use of digital telephony which, correctly applied (by qualified persons in data transmission and not by simple "smart phones" users) can logarithmically decrease the number of victims in case of disasters.

\section{REFERENCES}

Buhoiu A. (1977), Secunde tragice, zile eroice, Ed. Junimea, Iaşi.

Chertic P. 1995, Bazele urgenţei medicale în medicina militară, BMMC, Bucureşti.

Crăciun I. (2001), Situaţii şi servicii de urgenţă, Editura Min. de Interne, Bucureşti.

Nicolae S., Dan M. (1995), Introducere în medicina dezastrelor, EDP, Bucureşti.

Steiner N. (2004), Exerciţiu simulat electronic de intervenţie medicală în caz de cutremur din judeţul Vrancea, MPM Edit Consult, Bucureşti.

***, Emergency and Humanitarian Action (1997), 1996 Activities, WHO, Geneva.

www.romania-actualitati.ro, April 2016.

www.phe.gov. 2017.

www.zf.ro, Jan. 2014.

www.ziartop.ro, June2017.

www.digi24.ro/stiri/, Dec. 2017.

www.armataromaniei.ro, august 2015.

www.stiri.tvr.ro, August 2013.

www. 2isye/gatech.edu, Dec. 2017.

www.armataromaniei.ro/armata/4/842215452463017105 4067194611174, August 2015.

www.cnc.gov.ro/wp-content/,Situația numărului de spectatori înregistrat de filmele românești ieșite în premieră până la 31.12.2014" (PDF).

www.adevarul.ro/locale/ploieşti, August 2015. 